NBER WORKING PAPER SERIES

\title{
ACHIEVING PRICE STABILITY BY MANIPULATING THE CENTRAL BANK'S PAYMENT ON RESERVES
}

\author{
Robert E. Hall \\ Ricardo Reis \\ Working Paper 22761 \\ http://www.nber.org/papers/w22761 \\ NATIONAL BUREAU OF ECONOMIC RESEARCH \\ 1050 Massachusetts Avenue \\ Cambridge, MA 02138 \\ October 2016, Revised July 2017
}

A previous version of this paper circulated in 2014 under the name "Controlling Inflation under New Style Central Banking." Hall's research was supported by the Hoover Institution, while Reis's work was initially supported by a grant from INET and later by a grant from the ERC. This research is part of the National Bureau of Economic Research's Economic Fluctuations and Growth, and Monetary Economics Programs. We are grateful to Andy Atkeson, Marco Del Negro, Isabel Horta Correia, Narayana Kocherlakota, Monika Piazzesi, and Michael Woodford for helpful comments, and to Andrea Alati and Laura Castillo-Martinez for research assistance. The views expressed herein are those of the authors and do not necessarily reflect the views of the National Bureau of Economic Research.

At least one co-author has disclosed a financial relationship of potential relevance for this research. Further information is available online at http://www.nber.org/papers/w22761.ack

NBER working papers are circulated for discussion and comment purposes. They have not been peer-reviewed or been subject to the review by the NBER Board of Directors that accompanies official NBER publications.

(C) 2016 by Robert E. Hall and Ricardo Reis. All rights reserved. Short sections of text, not to exceed two paragraphs, may be quoted without explicit permission provided that full credit, including $\odot$ notice, is given to the source. 
Achieving Price Stability by Manipulating the Central Bank's Payment on Reserves

Robert E. Hall and Ricardo Reis

NBER Working Paper No. 22761

October 2016, Revised July 2017

JEL No. E31,E42,E58

\begin{abstract}
$\underline{\text { ABSTRACT }}$
Today, all major central banks pay or collect interest on reserves, and stand ready to use the interest rate as an instrument of monetary policy. We show that by paying an appropriate rate on reserves, the central bank can pin the price level uniquely to a target. The essential idea is to index payments on reserves to the price level and the target price level in a way that creates a contractionary financial force if the price level is above the target and an expansionary force if below. Our payment-on-reserves policy process does not require terminal conditions like Taylor rules, exogenous fiscal surpluses like the fiscal theory of the price level, liquidity preference as in quantity theories, or local approximations as in new Keynesian models. The process accommodates liquidity services from reserves, segmented financial markets where only some institutions can hold reserves, and nominal rigidities. We believe it would be easy to implement.
\end{abstract}

\author{
Robert E. Hall \\ Hoover Institution \\ Stanford University \\ Stanford, CA 94305-6010 \\ and NBER \\ rehall@gmail.com \\ Ricardo Reis \\ Department of Economics \\ London School of Economics \\ Houghton Street \\ London WC1 2AE \\ United Kingdom \\ r.a.reis@1se.ac.uk
}


We focus on the process of monetary policy - the way the central bank controls interest rates to stabilize the economy and achieve low and stable inflation. Before the 2008 financial crisis, central banks for decades adjusted nominal interest rates in interbank markets by changing a relatively small volume of reserves. This process for implementing monetary policy worked well in advanced countries and many less advanced ones, and while it was interrupted when nominal interest rates hit the zero lower bound, in principle, it could work equally well as soon as economies escape from the bound. Post crisis, central banks adopted a new process for monetary policy. Now, they maintain high reserves by paying close to market interest on them, and set the interest rate on reserves. Changes in the reserve rate quickly feed into changes in interbank and other short rates.

This new process of central banking comes with both challenges and opportunities. The literature so far has mostly focussed on the implications of having large volumes of reserves outstanding and the purchases of less liquid assets that they funded, generally longer-term government and corporate bonds. Quantitative easing policies, as they are known, on the one hand allowed central banks to respond to financial crises (Gertler and Karadi, 2013), but on the other hand may jeopardize their financial stability because higher interest rates lower portfolio values and increase the burden of interest payments (Hall and Reis, 2015). Less thought has been put into how this new process affects the ability of the central bank to control inflation (Reis, 2016a).

We study the use of payments on reserves to control inflation. Because the reserve rate controls other short rates, a central bank could follow the prevailing central-banking paradigm involving nominal interest rate rules, as laid out in Woodford (2003) and the extensive literature on the Taylor rule. But that literature has some disturbing elements - in particular, it rules out indeterminacy by assuming away explosive paths for inflation This paper reconsiders the fundamentals of the process by which a central bank intervenes in the economy to steer the price level. We propose a new process for setting the remuneration of reserves that is robust and free from the possibility of indeterminacy. We call it the robust reserve rate process.

Our proposal process combines two simple principles:

1. The asset that the central bank ordains to be the monetary unit has a purchasing power in terms of output that is the inverse of the price level: $1 / p$. 
2. In an economy with real interest rate $r$, if an entity issues a safe asset that pays off $1+r$ units of output next period, the current market price in terms of output is one.

Reserves are such an asset: they are the unit of account and the central bank pays interest on them. The conclusion is that if the payment on reserves is $1+r$ units next period, the price level today can only be 1 . Thus, the central bank has achieved its price level target with a monetary policy process that uses the payment on reserves as its instrument. The process depends only on observable financial variables and pins down the price level to its target uniquely and globally. To set the price level to a target greater than one, the central bank makes a payment on reserves that is proportionally lower, so the purchasing power of a unit of reserves is lower and its reciprocal, the price level, is higher.

In an economy with a fully flexible price level and price-level neutrality, in the sense that the real interest rate $r$ is independent of the price level, the central bank chooses the price level by setting its payment on reserves to $r$. Absent price-level neutrality, the central bank's choice of payment on reserves affects both the interest rate and the price level. But it remains the case that the economy's equilibrium involves a combination of a price level and an interest rate that satisfies the condition that the return from holding reserves equals the economy's real interest rate. If the price level is partially flexible, the central bank can set the price level to a target within the set of feasible price levels; the interest rate will be high if the target price is low within that set and low if the target price is high. If the price level is completely fixed, the central bank's choice of payment on reserves sets the interest rate to achieve financial equilibrium but cannot achieve a price level different from the fixed level.

This result generalizes to any asset issued by the central bank as long as (i) it is the monetary unit and (ii) the central bank sets its remuneration. This applies to a variety of deposits by financial institutions at the central banks around the world, including in the United States bank reserves, balances in overnight reverse repurchase agreements, and term deposits at the Federal Reserve. Moreover, a generalization of the payment promised on reserves yields a policy that makes the price level or inflation rate variable over time, not necessarily a price level fixed at 1 with zero inflation.

This paper probes the foundations of this process of price setting. Throughout the paper, we make a terminological distinction between the process of monetary policy - the way the central bank intervenes to set the price level - and the monetary policy rule - the way the 
central bank chooses the price-level target. The paper is almost entirely about the process and deals only tangentially with the rule. We start by writing a minimal model that involves only a no-arbitrage condition between reserves and nominal and real bonds. This setup is at the heart of the majority of more involved models in modern monetary and financial economics. We use it to show three equivalent ways of formulating the payment on reserves process, and prove that they deliver a globally unique price level.

We then show that our point continues to hold when firms set prices subject to nominal rigidities. The analysis takes into account equilibrium in goods and labor markets, as well as asset markets. A payment on reserves process uniquely pins down nominal income in that model, where the split between prices and output is determined by the extent of nominal rigidities.

Next, we deal with implementation issues. We show that mismeasurement of targets and economic conditions does not affect the determinacy of the price level, though it makes it harder for the central bank to hit its precise target. We also show that as long as the central bank pays its net income as dividends to the fiscal authority every period, its financial stability is guaranteed. A commitment by the fiscal authority to respect this arrangement, together with the usual commitment to a fiscal policy that satisfies the government intertemporal budget constraint under all possible realizations of random events, is all that is needed as fiscal backup to the central bank.

The following three sections consider three separate issues in our theory of the price level. First, we show that our conclusions follow through under several models of nominal rigidities. Second, we show that the price level continues to be determined by our process if reserves are a special asset in the sense of providing liquidity services. Third, we show that if the holders of reserves are subject to some financial frictions that break the no-arbitrage relation between reserves and other short-term government liabilities, a modified version of our process can be used to target inflation.

We postpone a discussion of the literature to the end of the paper. The determinacy of the price level under interest-rate rules has generated an enormous and controversial literature. The ideas in this paper provide a way to solve these problems. We show that our proposal avoids the issues of stability and determinacy that have arisen in studies of the Taylor rule. Moreover, unlike fiscal and monetarist theories of the price level, our approach does not rely on the government budget constraint or on a downward-sloping demand for liquidity, but 
rather follows from the use of arbitrage in financial markets. Our proposal has its roots in Irving Fisher's suggestion that the price level could be stabilized by defining the dollar as enough gold to buy the cost-of-living bundle, as discussed in Hall (1997). Here, we link that idea to the payment of interest on reserves, which expands its generality and implications.

The overall conclusion is twofold. Having large amounts of outstanding reserves and paying interest on them makes price-level stabilization easier. And a payment on reserves process provides an effective solution to the central problem of keeping the price level or inflation on target.

\section{The Robust Payment-on-Reserves Process}

The idea behind a payment-on-reserves process is straightforward, and its workings rely on a minimal set of assumptions. This section lays those out and explains how the process can be implemented in operationally different, but substantively equivalent ways.

The central bank maintains accounts, called reserves, for its customers, denominated in a monetary unit, which we will call the drachma. All prices in the economy are quoted in drachmas: one unit of output costs $p_{t}$ drachmas. The central bank makes a payment each period proportional the number of drachmas an investor has held with the bank from one period to the next. The amount of the payment is the bank's policy instrument, and is announced in advance at the time of the deposit. In this section, we consider two polar opposite economies in which a bank might operate. In one, the flexible-price economy, the price level responds freely to the bank's announced payment on reserves. In the other, the current price level is fixed, in the sense that it does not respond at all to the current announcement of the payment to be made next period. In the following sections, we take up cases with a sticky but not completely fixed price level.

In the economy with a flexible price level, the object of policy is to set the current price level $p_{t}$ to a target $p_{t}^{*}$. This target can vary over time and depend on other macroeconomic variables as determined by a monetary policy rule. We show that the central bank can achieve that target by setting the reserve payment according to a simple formula. In the case of an unresponsive price level, we show that the bank can set the real interest rate to a target level, by adjusting the return it pays on reserves to that level. 


\subsection{A minimal model}

We make two assumptions. First, that there are reserves, which are one-period debt claims on the central bank held by financial institutions. Reserves are the unit of value in every modern economy that we know of. By government declaration, their price is 1 drachma. The real value of a unit of reserves is therefore $1 / p_{t}$. Moreover, the central bank can choose how to remunerate the holders of the reserves. Most central banks have long held the authority to make payments on reserves, including the ECB and the central banks of Australia, Britain, Canada, Japan, New Zealand, Norway, and Sweden, and, since October of 2008, the United States as well. Finally, we also assume that the central bank is always able to honor the promised payment on reserves, and that reserves are provided in sufficient quantity that their market is saturated in the sense that they carry no liquidity premium. We will later show that the results are not sensitive to these last assumptions.

Reserves are priced in the market like other financial assets. This leads to our second assumption, which is at the bedrock in most modern financial economics: there are no arbitrage opportunities in financial markets - every asset's price is equal to the value of its payoff. A universal stochastic discounter $m_{t, t+1}$ gives the real value of any future real payoff:

$$
\mathbb{E}_{t}\left(m_{t, t+1} y_{t+1}\right)
$$

Here $y_{t+1}$ is a random real payoff and $\mathbb{E}_{t}(\cdot)$ is the expectations operator.

The central bank can observe the price of two assets: a real bond and a nominal bond. The inverse of the first price is the real interest rate, $r_{t}$, the real return to a security that pays one unit of output or real purchasing power:

$$
\frac{1}{1+r_{t}}=\mathbb{E}_{t}\left(m_{t, t+1}\right)
$$

The nominal interest rate, $i_{t}$ is the nominal return to a security that pays one drachma next period:

$$
\frac{1}{1+i_{t}}=\mathbb{E}_{t}\left(m_{t, t+1} \frac{p_{t}}{p_{t+1}}\right)
$$

The no-arbitrage assumption is that the real return to a unit of reserves equals the real return on other one-period safe financial instruments. The principle also implies equality of nominal interest rates paid on reserves and on other safe one-period nominal instruments. 


\subsection{A real-payment-on-reserves process}

The central bank chooses how much to pay banks for holding reserves. It uses this payment as the instrument of monetary policy. We consider a time-varying process specifying the payment of output next period:

Definition 1 A real payment-on-reserves central bank policy process pays the holder of a unit of reserves $1+x_{t}$ units of output next period; $1+x_{t}$ is set in period $t$.

The real value of a reserve in period $t$ is $1 / p_{t}$, so the return ratio under this process is

$$
\frac{1+x_{t}}{\frac{1}{p_{t}}}=\left(1+x_{t}\right) p_{t} .
$$

The condition for equality of the return ratio to the market return ratio $1+r_{t}$ is

$$
\left(1+x_{t}\right) p_{t}=1+r_{t} .
$$

With a flexible price level and a fixed market return ratio, the price level will equate the real returns at

$$
p_{t}=\frac{1+r_{t}}{1+x_{t}} .
$$

That is, the price level is the ratio of the gross real return ratio in financial markets in general, $1+r_{t}$, to the payment on one unit of reserves, $1+x_{t}$. The price level achieves financial equilibrium when the gross real return ratio, $\left(1+x_{t}\right) p_{t}$, equals the market return ratio, $1+r_{t}$.

The foregoing results lead to a key conclusion:

Proposition 1 With a flexible price level and fixed market real interest rate, if the central bank sets the real payment on reserves to

$$
1+x_{t}=\frac{1+r_{t}}{p_{t}^{*}},
$$

the unique price level is $p_{t}=p_{t}^{*}$.

The central bank's monetary policy rule specifies the price level $p_{t}^{*}$ to be achieved by the process of making real payments on reserves.

The real-payment-on-reserves process pins down the price level because the market equalizes the return on reserves to the real interest rate. Crucially, note that $1+x_{t}$ is not the return ratio on reserves. It is a payment amount, not a return ratio. The same payment is 
made in the future to a holder of a drachma of reserves regardless of the current purchasing power of that unit. Providing a stated payoff to the holder of one nominal unit of reserves is the basic idea of this approach to price stabilization. It ensures that the forces of arbitrage lead to changes in the real value of the reserves, which must come through changes in the price level.

This process is not the same as a policy of exchanging one unit of reserves for a stated number of units of a commodity. Under that kind of process, such as the gold standard, the central bank stands ready to exchange reserves for gold in both directions. The economic logic for price stabilization under a gold standard in Goodfriend (1988) is different from the logic behind our proposition. With a payment-on-reserves process, the economic force at play is the absence of arbitrage among financial assets, not the forces that keep relative prices of physical products at equilibrium levels. It is the financial market forces of equating the value of identical claims on future payoffs that stabilize the price level, not forces in goods market.

In an economy with a flexible price level, manipulating the payment on reserves gives the central bank immediate, total control of the price level. This result is simple, yet remarkable in its implications. A skeptical reader may question how the proposition may depend on the two assumptions we made, on whether it can credibly be implemented, and on whether this idea is a complicated reworking of a simpler one already in the literature. We address these concerns in the remainder of the paper. Before doing so, we consider two other ways the central bank could peg the price level by adopting a formula for paying holders of reserves.

In the case of a fixed price level and flexible real interest rate, the principle of equal returns to reserves and other one-period safe real returns dictates that the market real return ratio is

$$
1+r_{t}=\left(1+x_{t}\right) p_{t}
$$

The central bank has the power to peg the real return to all one-period safe real instruments.

\subsection{An indexed payment-on-reserves process}

The process in definition 1 requires delivering commodities to holders of reserves. If the delivery is specified in units of a commodity, like gold, then it is the price of gold that is stabilized, not the price of the cost-of-living bundle as desired. It would be impractical to 
deliver the entire bundle, which contains thousands of goods and services. Fortunately, there is an easy alternative:

Definition 2 An indexed payment-on-reserves monetary-policy process pays the holder of a unit of reserves $1+x_{t}$ times the value of the price index $p_{t+1}$ next period.

Under this process, the central bank issues price-level-indexed reserves in the same way that the treasury issues price-level-indexed bills. It promises a payment in drachmas, so there are no complexities or legal obstacles. The practice of indexing a payment on a governmentissued asset to a public cost-of-living statistic is already common in many countries, where fiscal authorities issue inflation-indexed bonds.

The real value of the payment on reserves is the same as discussed above, so the conclusions above also apply to reserves with indexed real payments.

Proposition 2 In the case of a flexible price level and fixed market real interest rate, if the central bank sets the indexed nominal payment on reserves to

$$
\left(\frac{1+r_{t}}{p_{t}^{*}}\right) p_{t+1}
$$

the unique price level is $p_{t}=p_{t}^{*}$.

In equilibrium, the central bank pays a real amount on reserves equal to the economy's observed real interest rate. We emphasize again that, although the payment is equal to the real interest rate, a policy of paying the real interest rate on reserves would not stabilize the price level at all. It is the policy of paying above the interest rate if the price level is below 1 and below the interest rate if the price level is above 1 that pegs the price level at 1 . Any

other price level creates a valuation anomaly, where two financially identical claims on the government have different returns. Only the target price level avoids that anomaly.

As before, in the case of a fixed price level and flexible interest rate, the central bank uses its instrument $x_{t}$ to peg the market real interest rate:

$$
1+r_{t}=\left(1+x_{t}\right) p_{t}
$$

\subsection{A nominal payment-on-reserves process}

A third alternative process for making payments on reserves involves only nominal quantities: 
Definition 3 A nominal payment-on-reserves monetary-policy process pays the holder of a unit of reserves a nominal amount of drachmas $1+x_{t}$ in period $t+1$; the amount is fixed in period $t$.

One unit of reserves costs 1 drachma in period $t$ and pays out $1+x_{t}$ drachmas in period $t+1$, so its nominal return ratio is $1+x_{t}$. Financial equilibrium requires that the nominal return ratio for reserves equal the market nominal return ratio:

$$
1+x_{t}=1+i_{t}
$$

In the fixed-price case, the central bank is pegging the market nominal interest rate.

Proposition 3 In the case of flexible prices, if the central bank sets the nominal payment on reserves to

$$
\frac{\left(1+i_{t}\right) p_{t}}{p_{t}^{*}},
$$

the unique price level is $p_{t}=p_{t}^{*}$.

The proof is simple: no-arbitrage requires that in equilibrium

$$
1+i_{t}=\left(1+i_{t}\right) \frac{p_{t}}{p_{t}^{*}} .
$$

Accordingly, $p_{t}=p_{t}^{*}$.

The central bank can implement this process because it can readily observe the current values of the price level and short-term government bonds. Whereas in the earlier flexibleprice results, the central bank had to make the promised payment, as of period $t$, conditional on the real return on bonds, now it must make the payment conditional on the observed price level and nominal return on bonds. This is a feedback process, like the Taylor rule, where setting the policy tool as a function of the observed price level steers the equilibrium price level to its target.

\subsection{Summary and interest-rate spreads}

The three processes equivalently pin down today's price at $p_{t}^{*}$, but they differ in the form their payment is arranged. The following table summarizes their properties. The second column shows the payment the reserve-holder receives in period $t+1$, the third column gives the units of that payment, either output (real) or drachmas (nominal), and the fourth column 
is clear about when the payment is determined. The fifth column restates the payment in real terms by dividing by $p_{t+1}$. The sixth and final column states the value of that payment as of date $t$, by applying the valuation operator to the payoffs in the previous column. All three entries in that column are the same and equal to $1 / p_{t}^{*}$. Because the asset with these payoffs is the unit of account, with a fixed real value $1 / p_{t}$, it follows that $p_{t}=p_{t}^{*}$.

\begin{tabular}{lclccc}
\hline \hline Process & Payment & Units & Known at & Real & Value \\
\hline Real & $\frac{1+r_{t}}{p_{t}^{*}}$ & Output & $t$ & $\frac{1+r_{t}}{p_{t}^{*}}$ & $\frac{1}{p_{t}^{*}}$ \\
Indexed & $\frac{1+r_{t}}{p_{t}^{*}} p_{t+1}$ & Drachmas & $t+1$ & $\frac{1+r_{t}}{p_{t}^{*}}$ & $\frac{1}{p_{t}^{*}}$ \\
Nominal & $\frac{1+i_{t}}{p_{t}^{*}} p_{t}$ & Drachmas & $t$ & $\frac{1+i_{t}}{p_{t}^{*}} \frac{p_{t}}{p_{t+1}}$ & $\frac{1}{p_{t}^{*}}$ \\
\hline \hline
\end{tabular}

One way of thinking about the three processes is in terms of the spread between the interest rate that reserves earn and the market rate. For the first two processes, the relevant spread is between the real return on reserves and the market real rate. It is equal to:

$$
\left(1+r_{t}\right) \frac{p_{t}}{p_{t}^{*}}-\left(1+r_{t}\right)=\left(1+r_{t}\right)\left(\frac{p_{t}}{p_{t}^{*}}-1\right) .
$$

For the third process, the spread between the nominal return offered by the central bank on reserves and the market nominal rate is:

$$
\frac{1+i_{t}}{p_{t}^{*}} p_{t}-\left(1+i_{t}\right)=\left(1+i_{t}\right)\left(\frac{p_{t}}{p_{t}^{*}}-1\right) .
$$

In all cases, unless the spread is zero, meaning that $p_{t}=p_{t}^{*}$, the basic financial no-arbitrage condition fails.

These spreads are hypothetical - they describe what would happen in an economy that did not obey the no-arbitrage condition. That condition requires that the spreads are zero. But, as we have stressed earlier, a process of paying an interest rate on reserves equal to the market rate would have no power to control the price level. It would satisfy the no-arbitrage condition for all price levels, not just the target level.

\section{General Equilibrium and Price Adjustment}

The minimal model discussed the determination of the price level without any mention of who sets prices. Moreover, the price level, or output, were determined by financial markets 
without any consideration for what goes on in goods or labor markets. While this approach is common in the study of price level determinacy using interest rates, such as Woodford (2003), this section spells out more clearly how prices and output are determined in general equilibrium when firms choose prices. The model is purposely simple and special — we extend it in many dimensions in the remainder of the paper.

\subsection{Households and no-arbitrage}

There is a representative agent, who chooses the amounts, $c_{t}(\omega)$, with $\omega \in[0,1]$, of varieties of goods to consume that are combined into an aggregate consumption, $c_{t}$. The agent also chooses labor supply, $\ell_{t}$, to maximize:

$$
\mathbb{E}_{0} \sum_{t=0}^{\infty} \beta^{t}\left(\log c_{t}-\ell_{t}\right) \text { with } c_{t}=\left(\int_{0}^{1} c_{t}(\omega)^{\frac{\gamma-1}{\gamma}} d \omega\right)^{\frac{\gamma}{\gamma-1}} .
$$

The parameter $\beta$ is the discount factor and $\gamma>1$ is the elasticity of substitution across varieties of goods.

The household can trade in three financial assets, as discussed in the previous section: one-period real notes with real return ratio $1+r_{t}$, nominal one-period bonds, with real return ratio $\frac{\left(1+i_{t}\right) p_{t}}{p_{t+1}}$, and reserves, with real return ratio $\left(1+x_{t}\right) p_{t}$. Both types of notes have zero net supply and reserves have exogenous positive net supply $v_{t}$, large enough so that the market is saturated with reserves, which therefore do not deliver liquidity services.

The consumer faces two constraints, a no-Ponzi-scheme condition stating that wealth at infinity must be non-negative, and a period resource constraint:

$$
\int_{0}^{1} p_{t+1}(\omega) c_{t+1}(\omega) d \omega+v_{t+1} \leq w_{t+1} \ell_{t+1}+z_{t+1}-\tau_{t+1}+p_{t+1}\left(1+x_{t}\right) v_{t}
$$

For simplicity, we have omitted the terms for the notes that are in zero net supply. The price of each good variety is $p_{t}(\omega)$, which aggregate to a price level $p_{t}$, and the nominal wage is $w_{t}$. The household earns labor income, profits from firms $z_{t}$ and pays lump-sum taxes $\tau_{t}$.

The within-period first-order conditions with respect to the varieties consumed $\left(c_{t}(\omega)\right)$ and labor supply $\left(\ell_{t}\right)$ are:

$$
\begin{aligned}
p_{t} c_{t} & =w_{t} \\
c_{t}(\omega) & =c_{t}\left(p_{t}(\omega) / p_{t}\right)^{-\gamma} \\
p_{t}^{1-\gamma} & =\int_{0}^{1} p_{t}(\omega)^{1-\gamma} d \omega .
\end{aligned}
$$


In turn, intertemporal optimization implies that the consumer's stochastic discounter is $m_{t, t+1}=\beta c_{t} / c_{t+1}$. Across periods, the first-order conditions for real notes, nominal notes, and reserves are:

$$
\begin{aligned}
\mathbb{E}_{t}\left[m_{t, t+1}\left(1+r_{t}\right)\right] & =1, \\
\mathbb{E}_{t}\left[m_{t, t+1} \frac{\left(1+i_{t}\right) p_{t}}{p_{t+1}}\right] & =1, \\
\mathbb{E}_{t}\left[m_{t, t+1}\left(1+x_{t}\right) p_{t}\right] & =1
\end{aligned}
$$

These three conditions match the no-arbitrage conditions in the previous section.

In equilibrium $c_{t}=y_{t}$, aggregate output. Household optimization thus leads to an IS curve:

$$
\mathbb{E}_{t}\left(\frac{y_{t}}{y_{t+1}}\right) p_{t}=\frac{1}{\beta\left(1+x_{t}\right)} .
$$

A higher value of $x_{t}$, which implies a higher real interest rate, depresses current output $y_{t}$ (relative to future output $y_{t+1}$ ) and depresses the current price level $p_{t}$. The Phillips curve, which we derive next, controls the split between the output effect and the price effect.

\section{$2.2 \quad$ Firms and price setting}

Each firm has a production function

$$
y_{t}(\omega)=\ell_{t}
$$

Firms are monopolistically competitive in each of the varieties. Equation (19) implies that the elasticity of demand for a variety is $-\gamma$. We assume that firms receive a sales subsidy of $1 /(\gamma-1)$ from the government. Therefore, a firm that has full information chooses $p_{t}(\omega)$ to maximize:

$$
\left(\frac{\gamma}{\gamma-1}\right) p_{t}(\omega) y_{t}(\omega)-w_{t} \ell_{t}(\omega) \text { s.t. } y_{t}(\omega)=c_{t}(\omega)=c_{t}\left(\frac{p_{t}(\omega)}{p_{t}}\right)^{-\gamma} \text {. }
$$

The fully flexible firm sets a price equal to the marginal cost, which is simply the nominal wage $w_{t}$.

To introduce nominal rigidities, we assume that only a fraction $\lambda$ of firms sets prices with full information. The remaining $1-\lambda$ set their prices at the start of the period, before observing the information that becomes available at time $t+1$. We assume they set their price to the nominal wage, $E_{t}\left(w_{t+1}\right)$, expected based on stale information. This simple model 
of nominal rigidities captures the main insights of New-Keynesian economics - see Woodford (2003) and Mankiw and Reis (2010).

Because firms differ along only this dimension, the price index in equation (20) becomes:

$$
p_{t+1}^{1-\gamma}=\lambda w_{t+1}^{1-\gamma}+(1-\lambda) \mathbb{E}_{t}\left(w_{t+1}^{1-\gamma}\right)
$$

From the labor supply equation (18), and because consumption equals output, the wage is: $w_{t}=p_{t} y_{t}$. Replacing this in the previous expression and rearranging gives:

$$
y_{t+1}^{1-\gamma}=\frac{1}{\lambda}-\frac{(1-\lambda) \mathbb{E}_{t}\left(p_{t+1} y_{t+1}\right)^{1-\gamma}}{\lambda p_{t+1}^{1-\gamma}} .
$$

This equation is the Phillips curve or aggregate supply curve.

If prices are fully flexible, so $\lambda=1$, this equation shows that output is one. The stochastic discount factor is then equal to $\beta$, so the real interest rate is $1 / \beta-1$. This "natural" economy corresponds to the case in the previous section where monetary policy has no effect on the real interest rate. With a lower $\lambda$, whenever nominal income is above what was expected, output exceeds one. A fraction $\lambda$ of firms raises their prices in response to shocks, while the others keep stale prices and raise their output to satisfy the resulting high demand.

\subsection{The central bank's revenue and expenses}

The fiscal authority issues no bonds. It sets taxes to cover the payment of subsidies minus the dividends received from the central bank:

$$
\tau_{t}=\frac{p_{t} y_{t}}{\gamma-1}-p_{t} d_{t}
$$

The central bank's resource constraint is:

$$
v_{t+1}=p_{t+1}\left[\left(1+x_{t}\right) v_{t}+d_{t+1}\right] .
$$

The central bank issues reserves to make payments on past reserves and to pay real dividends to the government. The central bank chooses the volume of reserves to issue each period. As long as the volume is sufficiently high to achieve saturation, it plays no role in the analysis, because Ricardian equivalence holds in the economy, and reserves are just a government liability.

Therefore, the central bank can choose $x_{t}$ as it pleases, and there is no doubt that there will always be available the resources to honor this promised payment. 


\subsection{Rational expectations equilibrium}

From the optimality condition involving real bonds, in equilibrium the real interest rate is

$$
r_{t}=\frac{1}{\beta E_{t}\left(y_{t} / y_{t+1}\right)}-1
$$

Monetary policy observes the real rate. It then chooses $x_{t}$ to follow the process:

$$
1+x_{t}=\frac{1+r_{t}}{p_{t}^{*}},
$$

where $p_{t}^{*}$ is an exogenous stochastic process. For simplicity, this is the only source of uncertainty in the economy. That is, the stochastic process for $p_{t}^{*}$ in the positive real line is defined on an exogenous $\sigma$-algebra and probability measure, with respect to which all variables in the model are measurable.

A rational-expectations equilibrium is then a solution for the stochastic processes $\left\{p_{t}, y_{t}\right\}$ as a function of the entire history of the exogenous stochastic process $\left\{p_{t}^{*}\right\}$, that satisfy:

$$
\begin{aligned}
y_{t+1}^{1-\gamma} & =\frac{1}{\lambda}-\frac{(1-\lambda) \mathbb{E}_{t}\left(p_{t+1} y_{t+1}\right)^{1-\gamma}}{\lambda p_{t+1}^{1-\gamma}}, \\
1+x_{t} & =\frac{1}{p_{t} \beta \mathbb{E}_{t}\left(y_{t} / y_{t+1}\right)}, \\
p_{t}^{*}\left(1+x_{t}\right) & =\frac{1}{\beta E_{t}\left(y_{t} / y_{t+1}\right)} .
\end{aligned}
$$

The determinacy question is whether there is a unique pair of processes $\left\{p_{t}, y_{t}\right\}$ that satisfies the three equations. ${ }^{1}$

The answer is a clear yes. Combining the last two equations, it follows that $p_{t}=p_{t}^{*}$. The first equation then uniquely pins down $y_{t}$.

Moreover, imagine that $p_{t+1}^{*}$ is unexpectedly higher. This corresponds to expansionary monetary policy, and implies a lower payment on reserves. The ratio on the right-hand side of the Phillips curve is unexpectedly low, thus $y_{t+1}$ rises with the surprise (recall that $\gamma>1$ ). The more flexible are prices, so $\lambda$ is closer to one, the smaller the increase in output, but if they are very rigid, the increase can be substantial. The payment on reserves process implies a unique equilibrium, and the extent of nominal rigidities pins down how much prices and output co-vary through the slope of the Phillips curve.

\footnotetext{
${ }^{1} \mathrm{~A}$ more formal way to state this is that an equilibrium set of processes are two mappings $p_{t}\left(p^{* t}\right), y_{t}\left(p^{* t}\right)$ where superscript denotes the entire history of the exogenous stochastic process. An equilibrium is determinate if this mapping is unique.
} 
Intuitively, a payment-on-reserves process would work as follows in this economy: The central bank announces its target for the price level, and promises a corresponding payment to the holders of reserves. In a given period, if the candidate price level is higher than the target, a positive spread between reserves and other real returns occurs. Investors and consumers attempt to switch to reserves, and away from present consumption. This lowers product demand, and firms respond by cutting prices. The price level falls and the economy finds its equilibrium at the target price level. All this takes place in a flash of pseudo-time. The only visible price level is equal to the price target.

In this consumption-based model of financial markets, the representative agent shifts her savings across the three assets until there are no arbitrage opportunities. This shift of savings is what makes prices adjust: if the price of one asset is too high relative to reserves, then the consumer will want to shift all their savings away from that asset, so that its price will adjust down.

\subsection{Recursive equilibrium}

Assume now that the central bank does not follow the feedback process that we propose, but instead sets the real payment on reserves $x_{t}$ exogenously. While this is a different process for monetary policy than the one advocated in this paper, it is useful to consider it to understand the channels by which monetary policy affects outcomes in this economy, when policy chooses a payment on reserves.

For simplicity, and because this model has no interesting dynamics, we assume that $x_{t}$ is independently and identically distributed.

Many models of price determination have multiple equilibria, indexed by an extraneous variable, often called a sunspot variable. We consider such an extraneous variable, $\xi_{t}$, which is also i.i.d., and affects no fundamentals in the economy, so it is independent of $x_{t}$.

This economy has no state variables: the joint distribution of the price level, output, and the interest rate is the same every period.

Let a prime $\left({ }^{\prime}\right)$ denote a variable in the next future period and no prime indicate a current

value. A recursive equilibrium is a pair of functions $\{p(x, \xi), y(x, \xi)\}$ such that the following 
two equations must hold:

$$
\begin{aligned}
p(x, \xi) & =\frac{\mathbb{E}\left(1 / y\left(x^{\prime}, \xi^{\prime}\right)\right)^{-1}}{\beta(1+x) y(x, \xi)} \\
y\left(x^{\prime}, \xi^{\prime}\right)^{1-\gamma} & =\frac{1}{\lambda}-\frac{(1-\lambda) \mathbb{E}\left(p\left(x^{\prime}, \xi^{\prime}\right) y\left(x^{\prime}, \xi^{\prime}\right)\right)^{1-\gamma}}{\lambda p\left(x^{\prime}, \xi^{\prime}\right)^{1-\gamma}} .
\end{aligned}
$$

The expectations operator is conditional on $(x, \xi)$. The first equation is an IS curve, or Euler equation, combined with the process for monetary policy. The second equation is the Phillips curve.

An equilibrium of this global economic system is determinate if there is a single pair of functions $\{p(x), y(x)\}$ that solve the two equations. That is, our monetary policy process globally and uniquely pins down the price level and output if there is a single map between the fundamental and outcomes that does not depend on an extraneous variable.

First consider what happens if there is no uncertainty, because policy $x$ is deterministic and there are no sunspots. Absent uncertainty, the second equation shows that $y_{t}=1$. In turn, the first equation shows that $p_{t}=1 /\left(\beta\left(1+x_{t}\right)\right)$. The central bank uniquely pins down the price level. Because with certainty, the nominal rigidity does not bind, the central bank has no control over output.

Next, consider the case where policy is deterministic but there may be extraneous shocks. Then, the IS equation shows that because the expectation is independent of the state, the product of $p$ and $y$ does not depend on $\xi$. From the second equation it then follows that again $y=1$ so the equilibrium is unique. Again, the process for monetary policy uniquely pins down the price level and can steer it to the desired target.

Finally, take the stochastic $x_{t}$ case. Because uncertainty is i.i.d., expected future output is independent of monetary policy. The first equation shows that a higher $x_{t}$ implies a lower nominal income $p_{t} y_{t}$. The Phillips curve in the second equation then determines how the higher $x_{t}$ is split into higher prices and output separately. The higher is $\lambda$, the larger the movement in $p_{t}$ and the smaller the movement in $y_{t}$, and conversely for a lower $\lambda$. This happens uniquely, regardless of $\xi$.

If the central bank picks the reserves process to hit a stochastic target $p_{t}^{*}$, then the second equation shows how output responds to the shocks to the target, while the first equation confirms proposition 1 . This is perhaps clearer if the two equations are log-linearized around 
their expected value to equal:

$$
\begin{aligned}
\hat{p}+\hat{y} & =-\hat{x} \\
\hat{y} & =\left(\frac{1-\lambda}{\lambda}\right) \hat{p} .
\end{aligned}
$$

The payment on reserves process uniquely pins down nominal income. The Phillips curve then determines how much the price level and output move separately. Whichever is that split, the payment on reserves process ensures determinacy of the equilibrium.

The remainder of the paper extends this setup in many directions and proves the robustness of this result. The next section considers measurement problems, the following one a more general model of price adjustment and the possibility of sunspots, and the two remainder ones models where reserves provide liquidity and markets are segmented between consumers and banks within the household.

\section{Implementation}

Our results so far assumed: that the central bank chose a single remuneration for reserves, that reserves and bonds were one-period assets, that the central bank perfectly observes market interest rates and its price target, that reserves were the only asset issued by the central bank, and that the central bank always honors its commitments. This section evaluates these assumptions with respect to reality.

\subsection{Many interest rates}

Operationally, central banks set the rate paid on reserves and the rate charged to banks on loans from the central bank. A market among commercial banks determines an interbank rate. Because banks can deposit funds at the central bank, the rate on reserves puts a floor on the interbank rate. Because they can borrow from the central bank, that rate puts a ceiling on the interbank rate. In most countries, these two rates therefore establish a corridor in which the interbank rate fluctuates. In the past, most central banks in advanced countries operated under this corridor system for years. Following the crisis, many central banks moved to a floor policy where the economy is saturated with reserves so the interbank rate equals the rate on reserves - see Reis (2016a). This configuration allows the central bank to control the volume of reserves in the system independently from the policy rate. 
Our reserve payment-on-reserves process is robust to whether central banks in the future stay with a floor, or move back to a corridor. In the former case, our process also pins down the interbank rate. In the latter, then liquidity in the system will determine the position of the interbank rate within the corridor, but the payment-on-reserves process still pins down inflation to the level dictated by the monetary policy rule (section 5 will expand on the effect of liquidity).

Our general process is also robust to idiosyncratic features of money markets and central banks in advanced countries. In particular, the specific properties of deposits at the central bank are different across countries, but as long as these deposits are the unit of account and as long as the central bank can choose how to remunerate them, our analysis applies. For instance, in the United States, the interest rate the Federal Reserve pays on reserves does not set a floor on the interbank rate, but a second type of borrowing from financial institutions in the repo market at the policy rate performs that role. Our process can be applied to the payment in these repo market deposits.

\subsection{Maturity of reserves}

In this paper, we take reserves to be one-period instruments. As a practical matter, holders of reserves do not have to roll their holdings every period. Under certain conditions, such as in the economy described by Samuelson (1958), reserves could have values higher than the present values of their earnings. We do not think this is a realistic outcome. If it were a danger, central banks could change reserves to have call rights.

Another operational detail is that the market interest rates, real or nominal, to which the payment on reserves should be indexed, often are only well measured in liquid financial markets of 90-day maturities, while the deposits at the central bank are overnight. Of course nothing prevents the central bank from accepting term deposits of 90 days or other maturities. More generally, this raises the issue of mismeasurement of interest rates to which we now turn.

\subsection{Measurement of interest rates}

The instrument of policy to keep the price level on target considered in this paper rewards a drachma of reserves with a payment indexed positively to the future or current price and negatively to the desired price. The processes are easy to implement because they are simple, 
verifiable, and require little information. The real and indexed versions require observing the current return on a one-period treasury indexed bill. In addition, the indexed version requires the central bank and the treasury to observe the price level next period to implement payments. The nominal version requires observing the current return on a nominal treasury bill and the current price level.

In advanced countries, continuous trading of large volumes of both indexed and nominal government debt essentially eliminates measurement errors in the corresponding returns. However, in the United States, indexed government debt is not indexed to reduce nominal payoffs if the price level is lower at maturity than at issue, so inferring the safe real rate from the market price of indexed debt is tricky. Further, there are suspicions that indexed debt may have a general tendency toward higher realized returns than nominal debt, and little doubt that this was true in late 2008. At the same time, there are suspicions that, even when the amounts outstanding are huge, nominal treasury bills have realized real riskadjusted returns below those of other instruments (Fleckenstein, Longstaff and Lustig, 2014).

For both the real and nominal processes, biases in inferring returns result in biases in the price level relative to target. To see this more formally, assume that the central bank only has an estimate $r_{t}^{e}$ of the value of the real interest rate today. The actual value is:

$$
1+r_{t}=\left(1+r_{t}^{e}\right)\left(1+\varepsilon_{t}\right)
$$

where $\epsilon_{t}$ is a measurement error. In this case, implementing the policy process in proposition 1 leads to the equilibrium outcome:

$$
p_{t}=p_{t}^{*}\left(1+\varepsilon_{t}\right)
$$

These measurement errors are not due to the fundamental difficulty in estimating an unobservable quantity like the Wicksellian or equilibrium real rate of interest - see Cúrdia, Ferrero, Ng and Tambalotti (2015) and Holston, Laubach and Williams (2016). Rather, they refer to errors in reporting the actual prices in financial markets.

\subsection{The price level and its target}

Similar to interest rates, for both the indexed and nominal processes, errors in measuring the price level in real time will induce deviations of the resulting price from a target for the true price level. For the indexed version, the resulting price level is sensitive to errors in 
measuring the rate of price change but unaffected by errors in measuring the price level that are common to the beginning and ending prices. For the nominal version, the price level inherits measurement errors. To put it differently, the nominal process pegs the measured, not the true, price to $p^{*}$.

Some of this discrepancy between true and measured price level may be systematic. For instance, in the case of the United States, implementation would likely be based on the consumer price index, which is available in real time and is already used to index government bonds and many social benefits. But the Federal Reserve defines its mandate in terms of the price index for personal consumption expenditures. A good deal is already known about the close relationship between the two. Making the adjustment between the two should pose no great challenge.

Finally, although we have focused on a price target, $p_{t}^{*}$, we do not have in mind a singleminded devotion to strict price stability. Most practical macroeconomists, together with the governors of central banks, believe in price-level non-neutrality - the principle that a perturbation in a price-level target has important effects on real activity. In consequence, no central bank would follow a policy of setting the price level to a predetermined path $p_{t}^{*}$. Instead, the bank, following the principle that upward deviations of the price level are acceptable if deficient real activity accompanies them, would formulate a flexible price target in terms of:

$$
\log p_{t}^{*}=k_{t}+\alpha\left(u_{t}-u_{t}^{*}\right)
$$

where $u_{t}$ is unemployment expressed as a decimal, $u_{t}^{*}$ a target or natural rate, $\alpha$ is a parameter, and $k_{t}$ is the long-run mandate of the central bank, for instance $2 \%$ price level increase on average, in which case $k_{t}=0.02 t$. Hall (1984) called this approach to central-bank policy an "elastic price standard" and Ball, Mankiw and Reis (2005) showed it was optimal in new Keynesian models. Woodford (2003) provides a comprehensive treatment of how monetary policy can pursue a dual mandate of price and economic stability. Central banks tend to set targets for the inflation rate rather than the price level, despite the case that price-level targeting is superior. That is, they set $k_{t}=0.02+p_{t-1}$.

Advocates of price-level or inflation targeting start with the assumption that the central bank can reliably achieve the desired target. The complementary analysis in this paper describes a robust process linking the central bank's logical instrument, its payment on reserves, to the price level. In practice, we foresee that central-bank policy would set a real 
payment on reserves at a level intended to produce the right combination of price level and unemployment, then adjust the payment quite frequently to make up for any departures in the resulting combination of price level and unemployment. In effect, the central bank would use the real payment on reserves as a high-frequency policy instrument to peg the price level and unemployment rate to the desired relation to one another.

\subsection{Currency and the zero lower bound}

Central banks issue not only reserves but also currency, which exchanges one-to-one for reserves, but pays no interest. There is an enormous and contentious literature on why people hold currency. For our purposes, it is enough to simplify by adjusting our model from section 2 to change the utility function to be: $\log c_{t}-\ell_{t}+H\left(h_{t} / p_{t}\right)$. Currency is denoted by $h_{t}$, and the function $H(\cdot)$ is increasing and concave up to a satiation point $\eta$, after which more real currency balances have no effect on utility. The budget constraint of the households now includes a new term equal to the use of funds by seignorage:

$$
s_{t}=\frac{h_{t}-h_{t-1}}{p_{t}} .
$$

Seignorage is revenue for the central bank and so enters as a source of funds in its resource constraint. Finally, the households face a constraint $h_{t} \geq 0$ since they cannot short currency. Otherwise, nothing in the model changes.

The Euler equations still lead to the same no-arbitrage conditions that we used in section 1. The payment on reserves process therefore can still uniquely and globally pin down nominal income. The split between the price level and output is still determined by the interaction of shocks and nominal rigidities as in section 2. The only change is that there is a new optimality condition in the household's problem:

$$
c_{t} H^{\prime}\left(h_{t} / p_{t}\right) \leq \frac{i_{t}}{1+i_{t}}
$$

with strict equality if real currency balances are positive. The demand for currency rises as $i$ falls. It becomes perfectly elastic at the point where real balances are above the satiation level. In equilibrium, currency displaces a volume of reserves so that the real stock of currency satisfies this condition. We assume that the remaining volume of reserves still achieves saturation.

With currency, the central bank may not be able to implement the price-level target it wants. The left-hand side of equation (44) is always non-negative. Currency puts a constraint 
on the right-hand side, the zero lower bound for the nominal interest rate: $i_{t} \geq 0$. Using the arbitrage condition between nominal bonds and reserves, together with the process for reserves, this puts a constraint on how much can be paid on reserves

$$
1+x_{t} \geq\left(1+r_{t}\right) \mathbb{E}_{t}\left(\frac{m_{t, t+1}}{p_{t+1}^{*}}\right) .
$$

A lower payment than this would lead agents to want to hold an infinite amount of currencyand zero reserves or any other asset - which cannot be an equilibrium. In other words, the payment on reserves process does not allow the central bank to avoid the zero lower bound. Thus, expected deflation cannot fall below the real rate of interest.

\subsection{Central bank financial stability and fiscal backing}

The propositions assumed no default premium, because the monetary policy process promises a payment on reserves is always honored. No central bank has yet defaulted in an advanced country. However, with trillions outstanding in reserves, the central bank may not have the resources to stick to a process that promises to make payments on those reserves. Hall and Reis (2015) discuss at length the financial stability of a central bank, and how interest-paying reserves may put it at risk or not. Here, we apply that analysis to the case of a central bank that follows a payment-on-reserves process.

In the model in section 2, the central bank always had the real resources to satisfy its promises because the fiscal authority could always deliver the goods via negative dividends and lump-sum taxes. Imagine now that the central bank is independent, which translates into a lower bound for the flow of real dividends from the central bank to the fiscal authority $d_{t}$ for the process for dividends. For simplicity, assume that the central bank buys only short-term nominal government bonds and that these never default. With $b_{t}^{c}$ denoting the bonds held by he central bank today that are due next period, the central bank's resource constraint is:

$$
v_{t+1}=p_{t+1}\left[\left(1+x_{t}\right) v_{t}-s_{t+1}+d_{t+1}\right]-b_{t}^{c}+\left(\frac{1}{1+i_{t+1}}\right) b_{t+1}^{c} .
$$

Real seignorage earned from printing currency minus the expenses of running the central bank are denoted by the net flow of revenue $s_{t}$ in units of output.

Most central banks are obligated to rebate to the fiscal authorities their net income periodically. Hall and Reis (2015) show that this implies that the net worth of the central 
bank is constant. The central bank is always financially stable because its net liabilities are not exploding or violating a no-Ponzi scheme condition. We let $n_{t} p_{t}=b_{t}^{c} /\left(1+i_{t}\right)-v_{t}$ denote net worth, which is constant at $n$. Under a payment on reserves process that delivers a price level on target, the appendix shows that the law of motion for reserves implies that the dividend is equal to:

$$
d_{t+1}=s_{t+1}+r_{t} n+\frac{b_{t}^{c}}{p_{t}}\left(\frac{p_{t}}{p_{t+1}}-\frac{1+r_{t}}{1+i_{t}}\right) .
$$

The return on the initial net worth of most central banks usually more than offsets the rare years in which there is a contraction in the demand for banknotes; therefore, the first two terms on the right-hand side almost always provide a positive net income. In turn, the last term is zero in risk-adjusted expected terms: just multiply the expression in parentheses by the stochastic discount factor and take expectations. Therefore, on average the central bank can return a positive dividend to the fiscal authority. Only in periods where the central bank's price level target next period turns out to involve an unexpectedly large inflation relative to the one that was priced into real and nominal bonds may the central bank require a flow of funds from the fiscal authorities. These instances should be rare, and can be dealt with no recapitalization by maintaining a cushion from past income or withholding future dividends. Moreover, they can be avoided altogether if the central bank holds real bonds as opposed to nominal bonds as assets, in which case dividends would be given by the expression above without the last term on the right-hand side. The reason behind this term is the mismatch between the promised real payment on reserves and the nominal-paying assets that we assumed the central bank chooses to hold.

A separate issue is whether the central bank's monetary policy rule accords with the support of fiscal policy in the way it pays for its deficits. It is well known that any monetary policy is only consistent with a particular path for prices if the fiscal authority is committed to raising fiscal surpluses to pay for increases in the nominal public debt without relying on inflationary finance from the central bank - see Sims (2013). Throughout this paper, we assume that the government is committed to a fiscal policy that satisfies the intertemporal budget constraint. The payment on reserves does not modify this requirement for monetary dominance in any significant way relative to standard treatments. 


\section{Dynamic Models of Nominal Rigidities}

Section 2 showed that nominal rigidities do not change our point. They imply that achieving the price level target comes with changes in output as well, or that the effects of changing the payment on reserves now affects both the price level and the real interest rate.

A more general statement of price-level non-neutrality is that the economy's real interest rate depends on the current price level, so it is $r_{t}\left(p_{t}\right)$. The dependence of the function on time permits the history, possibly summarized by a state variable, to play a role. The mechanisms behind $r_{t}\left(p_{t}\right)$ are imperfectly understood and intensely controversial. But the payment-onreserves process stated in the proposition is robust to this function. Propositions 1 to 3 in section 1 are unchanged. As long as the central bank realizes that now $r_{t}$ depends on its target for the price level and adjusts the process accordingly, then it can still implement the process in proposition 1 and achieve the price level target. Its real payment on reserves becomes

$$
\frac{1+r_{t}\left(p_{t}^{*}\right)}{p_{t}^{*}}
$$

The logic for the global determinacy of the price level remains the same.

There is a more subtle complication. Imagine agents perceive that the central bank may deviate from this real payment by some exogenous amount. Suppose that the public believes that the central bank uses the payment-on-reserves process with a value of the real interest rate $z_{t}$ that may not equal the actual market value. In this case, the price level is:

$$
p_{t}=\frac{1+r_{t}\left(p_{t}\right)}{1+z_{t}} p_{t}^{*} .
$$

Uniqueness now depends on the shape of the function $r_{t}\left(p_{t}\right)$. More than one value of $p_{t}$ may exist that solve this equation. This sunspot indeterminacy is only possible because agents expect a deviation from the monetary policy process. The deviation feeds into real outcomes and real interest rates, so the rule may end up being self-confirming. At this level of generality, one cannot say more without writing a specific model of the Phillips curve. We therefore turn to three leading models of price adjustment. The appendix modifies the model of section 2 to account for them, so that below we jump right to the reduced form equations. 


\subsection{Sticky information}

The sticky information model posits that firms set their prices based on stale information, as a result of episodic updating arising from costs of updating information. In the formulation of Mankiw and Reis (2002), every period a fraction $\lambda \in(0,1)$ of firms randomly drawn from the population updates their information sets and makes plans for their future prices. The resulting dynamic model is:

$$
\begin{aligned}
\hat{p}_{t} & =\lambda \sum_{j=0}^{\infty}(1-\lambda)^{j} \mathbb{E}_{t-j}\left(\hat{p}_{t}+\alpha \hat{y}_{t}\right), \\
\hat{y}_{t} & =\mathbb{E}_{t}\left(\hat{y}_{t+1}\right)-\frac{1}{\sigma} \hat{r}_{t}, \\
\hat{p}_{t}-\hat{p}_{t}^{*} & =\hat{r}_{t}-\hat{z}_{t} .
\end{aligned}
$$

Hats over variables reflect their log-linear deviations from the steady state. The first equation is the Phillips curve (or AS equation) with $\alpha>0$ where $\hat{y}$ is the output gap, generalizing the model of section 2. The second equation is the log-linearized version of the Euler equation, just as in section 2, but generalized to allow for a general utility function with $\sigma>0$ equal to the inverse of the intertemporal elasticity of substitution. The third equation is the loglinearized version of the payment-on-reserves process in equation (49). The usual shocks in the equations of the model, to the natural rate of interest or markups, do not affect determinacy so they can be left out.

If policy follows the process we propose and agents believe it, then $\hat{z}_{t}=\hat{r}_{t}$. The price level is pinned to the target by the third equation. The Phillips curve then delivers the equilibrium for $\hat{y}_{t}$, and the IS curve determines $\hat{r}_{t}$. The equilibrium is locally determinate, naturally since it was globally unique.

In the presence of a sunspot shock, the determinacy of the price level requires an explosive dynamic response of the system to the shock. Otherwise, there would be a continuum of equilibria indexed by the shock. That is, letting tildes over the variables represent the impulse responses to a sunspot shock $t$ periods after, there is a sunspot equilibrium if $\tilde{p}_{t} \neq 0$ and the price level remains finite as time goes to infinity.

The system above implies that the responses to a sunspot shock would be given by:

$$
\begin{aligned}
\tilde{y}_{t+1} & =\tilde{y}_{t}+(1 / \sigma) \tilde{p}_{t} \\
(1-\lambda)^{t+1} \tilde{p}_{t} & =\alpha\left[1-(1-\lambda)^{t+1}\right] \tilde{y}_{t}
\end{aligned}
$$


Rearranging gives a single linear difference equation for the price level:

$$
\tilde{p}_{t}=\underbrace{\left[\frac{\frac{(1-\lambda)^{t}}{\alpha\left[1-(1-\lambda)^{t}\right]}+\frac{1}{\sigma}}{\frac{(1-\lambda)^{t+1}}{\alpha\left[1-(1-\lambda)^{t+1}\right]}}\right]}_{\equiv A_{t}} \tilde{p}_{t-1} .
$$

It is easy to see that $A_{t}$ is bounded uniformly above 1 for all $t$, so the system explodes. Thus, the payment-on-reserves process delivers a unique solution for the price level with sticky-information nominal rigidities.

\subsection{Sticky prices}

Calvo's (1983) model remains popular as a tractable account of inflation. It posits that a fraction $\lambda$ of firms change their prices each period, and are then stuck with that price until the next time they can adjust. The Phillips curve in the dynamic system is:

$$
\tilde{\pi}_{t}=\beta \mathbb{E}_{t}\left(\tilde{\pi}_{t+1}\right)+\kappa \tilde{y}_{t}
$$

where $\beta \in(0,1)$ is the discount factor, and $\kappa>0$ is the slope of the Phillips curve.

As before, we can analyze the determinacy of this dynamic system by looking at the response to an exogenous shock. The system is:

$$
\left(\begin{array}{c}
\tilde{\pi}_{t+1} \\
\tilde{y}_{t+1} \\
\tilde{p}_{t}
\end{array}\right)=\underbrace{\left(\begin{array}{ccc}
\frac{1}{\beta} & -\frac{\kappa}{\beta} & 0 \\
\frac{1}{\sigma} & 1 & \frac{1}{\sigma} \\
1 & 0 & 1
\end{array}\right)}_{\equiv A}\left(\begin{array}{c}
\tilde{\pi}_{t} \\
\tilde{y}_{t} \\
\tilde{p}_{t-1}
\end{array}\right) .
$$

The system has two jump variables, inflation and output, and one pre-determined variable. Therefore, saddle-path stability requires that two eigenvalues of the $A$ matrix are outside

of the unit circle and one is inside. A simple condition for this to be the case is that the characteristic polynomial for the $A$ matrix, $P(x)$ has the properties $P(1)<0$ and $P(-1)>0$. The appendix shows that these two conditions hold for this system. The payment-on-reserves process leads to a determinate price level with the baseline sticky price model.

\subsection{Adaptive price-setting}

The older accelerationist model of the Phillips curve is:

$$
\tilde{\pi}_{t}=\tilde{\pi}_{t-1}+\kappa \tilde{y}_{t} .
$$


It portrays firms as setting price increases that adapt gradually to changes in output.

The analysis is similar to that of the sticky price model, so we relegate it to the appendix. Again, the dynamic system can be written as a 3-equation system, but because now only output is forward-looking, the condition for determinacy is that one eigenvalue is larger than one, and the others are smaller. It is straightforward to prove that, again, the system is determinate for any parameter values, just as in the previous two cases.

Finally, a popular model of inflation dynamics in DSGE models is a hybrid of sticky prices and backward-looking behavior:

$$
\tilde{\pi}_{t}=\phi \tilde{\pi}_{t-1}+(1-\phi) \mathbb{E}_{t}\left(\tilde{\pi}_{t+1}\right)+\kappa \tilde{y}_{t}
$$

where $\phi \in[0,1]$. The appendix again shows that for any value of $\phi$, the payment-on-reserves process leads to price-level determinacy.

\section{$5 \quad$ Reserves that Provide Liquidity Services}

Our propositions rely on the equality of the real cost of holding a reserve to the real present value of its cash payoff. Reserves are priced in the same way as other financial assets, so that from the perspective of an investor, reserves should be no different from, say, short-term government bonds. With trillions of dollars of reserves currently outstanding, it seems reasonable to assume that whatever liquidity demand for reserves is satiated, and Reis (2016a) presents several pieces of evidence consistent with this view.

As time passes, central banks may eventually return to lean balance sheets where reserves are scarce and earn a significant liquidity premium over other assets. And, in a financial crisis, the demand for liquidity services provided by reserves increases so the premium may re-emerge. This subsection studies how a payment-for-reserves process works in a world in which the market for reserves is no longer saturated.

\subsection{A general result}

To take account of the liquidity services provided by reserves, we make one re-interpretation and one modification of our general model. The re-interpretation comes from noting that the stochastic discount factor may depend on the real amount of reserves outstanding. We make this dependence explicit by writing $m_{t, t+1}\left(v_{t} / p_{t} ; v_{t+1} / p_{t+1}\right)$. Recall that $v_{t}$ is the quantity of 
reserves outstanding. We show that the reserves process is robust to this modification, so our results apply even with substantial dependence of real reserves.

Our modification adds the value of the liquidity services to the cash payoff from holding reserves. Letting $\phi_{t}$ denote this service in drachmas, which may be random and depend on the quantity and return on reserves, the pricing condition for reserves is now:

$$
1=p_{t} \mathbb{E}_{t}\left(m_{t, t+1}\left(v_{t} / p_{t} ; v_{t+1} / p_{t+1}\right)\left(1+x_{t}\right)\right)+\phi_{t} .
$$

On the left-hand side, as before, is the price of reserves, which is equal to one since they are the unit of account. On the right-hand side is the sum of their purely financial value and their provision of liquidity services.

With this modification, the price level is still globally uniquely determined for an exogenous choice of $x_{t}$. The process that delivers prices on target is modified as follows:

Proposition 4 With a liquidity premium, if the central bank sets the real payment on reserves to

$$
1+x_{t}=\frac{\left(1+r_{t}\right)\left(1-\phi_{t}\right)}{p_{t}^{*}},
$$

the unique price level is $p_{t}=p_{t}^{*}$.

Two lessons emerge from this proposition. The first is that, even if reserves earn a premium return over other financial assets, as long as this premium is independent of the price level, the payment-on-reserves process still pins down the price level uniquely. In this case, the price level will deviate from the target in response to changes in that premium if the policymaker does not take fluctuations in this premium into account when setting the process. If instead the premium depends on the price level, as in the case of a non-vertical Phillips curve discussed in the previous section, as long as the policymaker takes this dependence into account, the payment-on-reserves process keeps the price level on target.

The second lesson is that the process is affected by the amount of reserves only via the liquidity premium. The size of the central bank's balance sheet may have an effect on financial stability or on financial repression in the overall economy, and so endogenously affects real outcomes, as in Greenwood, Hanson and Stein (2016). In our model, this shows up as the dependence of the stochastic discount factor on the amount of reserves. But as proposition 4 shows, and all the other propositions confirmed, this does not matter for the payment-on-reserves process. All of these effects are summarized in a sufficient statistic for 
price-level determination: the real interest rate. Any effect of issuing more or less reserves on the process would instead show up only directly through its effect on the size of $\phi_{t}$.

The remainder of this section shows that the proposition above, and the lessons that follow from it, are quite general: three separate standard models of these liquidity services all fit into the formulation above. They differ only in that they provide different microfoundations for which factors affect $\phi_{t}$ and $r_{t}$.

\subsection{Two old monetarist models}

The most common model of the liquidity services provided by different forms of money is the money-in-the-utility function model. It assumes that investors derive direct utility from holding reserves as in Sidrauski's (1967), so that preferences in our simple model in section 2 would be modified to now read: $U\left(c_{t}, v_{t} / p_{t}\right)-l_{t}$. Marginal utility with respect to reserves is strictly positive until a satiation point after which it becomes zero.

Another popular model of liquidity assumes that a liquid asset, like reserves, provides a means of exchange by lowering the effective cost of consumption. The utility of the representative agent is now still $U\left(c_{t}\right)-l_{t}$ but the costs of consumption in the budget constraint is now $p_{t} c_{t}\left(1-\tau\left(v_{t} / p_{t}\right)\right)$, where the function $\tau(\cdot)$ is again strictly increasing until a satiation level and constant and equal to 1 after that.

Both of these models are frequently used to generate a demand for liquidity. The optimality conditions derived in the appendix show that both fit into our setup above.

Lemma 1 The model of money in the utility function setup fits into our general setup with valuation operator and liquidity premium given by:

$$
\begin{aligned}
m_{t, t+1} & =\beta U_{c}\left(c_{t+1}, v_{t+1} / p_{t+1}\right) / U_{c}\left(c_{t}, v_{t} / p_{t}\right), \\
\phi_{t} & =U_{v}\left(c_{t}, v_{t} / p_{t}\right) / U_{c}\left(c_{t}, v_{t} / p_{t}\right) .
\end{aligned}
$$

The transactions-cost model implies a valuation operator and liquidity premium given by:

$$
\begin{aligned}
m_{t, t+1} & =\beta U_{c}\left(c_{t+1}, v_{t+1} / p_{t+1}\right)\left(1-\tau\left(v_{t+1} / p_{t+1}\right)\right) / U_{c}\left(c_{t}, v_{t} / p_{t}\right)\left(1-\tau\left(v_{t} / p_{t}\right)\right. \\
\phi_{t} & =c_{t} \tau^{\prime}\left(v_{t} / p_{t}\right)
\end{aligned}
$$

Therefore, the conclusions of proposition 4 hold.

In both models, if the central bank issues enough reserves, so that the market is saturated, $\phi_{t}=0$ and we are back in the analysis of sections 1 and 2. Further quantitative easing policies 
then have no effect on inflation. If instead the central bank chooses to make reserves scarce, then expansions and contractions in the size of its balance sheet will affect the liquidity premium. If the utility function is non-separable in consumption and reserves, as in the Sidrauski model, reserve balances may also affect the stochastic discount factor and the real interest rate. In this case, quantitative easing will create shocks that interest-rate policy has to counteract to keep the price level on target.

\subsection{A new-monetarist model}

The new-monetarist model launched by Lagos and Wright (2005) posits that agents trade in a decentralized market using the liquid asset through one-to-one bargaining, followed by trade in a centralized market where they can trade other assets free from transaction costs. We assume that reserves can serve the role of the liquid asset in the decentralized market. Interest is paid on these reserves in the centralized market as is the case with the return on other bonds.

The model involves extensive notation that is not crucial for our point, so we relegate it to the appendix. Important ingredients are that: (i) agents obtain utility from consumption in the centralized market $U\left(c_{t}\right)$ discounted by a factor $\beta$ and linear disutility from working $l_{t}$ hours at a wage $w_{t}$, (ii) prices are flexible, (iii) the household gets utility from consumption in the decentralized market $u\left(c_{t}\right)$ where production of quantity $q_{t}$ leads to an effort cost of $e\left(q_{t}\right)$, (iii) they are matched with others to trade in the decentralized market with probability $\sigma$, (iv) Nash bargaining in the decentralized market is such that the reserve balances entering the centralized market are given by an increasing function of what is produced $g(q)$. With these four ingredients in mind, the appendix proves the following result:

Lemma 2 The new monetarist model of liquidity fits into our general setup with valuation operator and liquidity premium given by:

$$
\begin{aligned}
m_{t, t+1} & =\beta U^{\prime}\left(c_{t+1}\right) / U^{\prime}\left(c_{t}\right), \\
\phi_{t} & =\left(\frac{\sigma \beta}{U^{\prime}\left(c_{t}\right)}\right) \mathbb{E}_{t}\left(\frac{u^{\prime}\left(q_{t+1}\right)-e^{\prime}\left(q_{t+1}\right)}{g^{\prime}\left(q_{t+1}\right)}\right) .
\end{aligned}
$$

Therefore, the conclusions of proposition 4 hold.

The liquidity premium in this model arises from the effect that carrying reserves has on the terms of trade in the decentralized market on the incentives facing consumers and 
producers. The central bank could drive this term to zero by saturating the market with reserves. The payment-on-reserves process delivers a unique price level.

\section{$6 \quad$ Segmented Financial Markets}

Reserves are a special asset. They are the unit of account, they never default, and the central bank controls both their quantity as well as their remuneration. These special properties enable the payment-on-reserves process to control the price level.

One other special feature of reserves in most advanced economics is that only financial institutions can hold them. In the United States, only banks can hold reserves, but since 2014, a broader set of financial institutions can also lend to the Fed in the overnight repurchase agreement market on terms that the Fed sets. The new asset, called an RRP, is effectively a reserve, and implementing our payment-on-reserves process in the United States would be done by having an equivalent payment on RRPs.

As long as these financial institutions compete for arbitraging away differences in returns between reserves and safe short-term bonds, then our results apply. This section studies the unlikely, but possible, case where this may not happen because of financial frictions in the financial sector that lead to a segmentation between the markets for bonds and for reserves.

\subsection{A general setup}

Segmented markets between two assets lead to positive or negative premiums in their returns. One way to model segmentation is to posit that there are two separate stochastic discount factors, one that applies to the payoff from reserves and a different one that applies to bonds. With segmentation, the two separate discounters can co-exist because there are no agents able to arbitrage the valuation disparity. Another way to interpret segmentation posits that the financial institutions that can hold reserves have a stochastic discount factor different from the agents that bonds. We do not think this is likely, but this section serves as a robustness check, and lets us discuss segmentation using some of the models of banks and financial frictions in the literature.

We introduce a new stochastic discount factor $m_{t, t+1}^{b}$ for banks, the holders of reserves. The equilibrium condition for reserves with a payment-on-reserves process becomes:

$$
1=p_{t} \mathbb{E}_{t}\left(m_{t, t+1}^{b}\left(1+x_{t}\right) .\right.
$$


Because this stochastic discount factor differs from the one that values indexed bonds, there is a value premium of reserves defined by:

$$
1+\chi_{t} \equiv \mathbb{E}_{t}\left(m_{t, t+1}^{b}\right)\left(1+r_{t}\right)
$$

This may be positive or negative and it may even vary over time, as the inability of agents to arbitrage this premium away may depend on the evolution of the economy.

Combining the two expressions above leads to a simple modification of our main result:

Proposition 5 With a reserves value premium, if the central bank sets the real payment on reserves to

$$
1+x_{t}=\frac{\left(1+r_{t}\right)}{\left(1+\chi_{t}\right) p_{t}^{*}}
$$

the unique price level is $p_{t}=p_{t}^{*}$.

Again, this modification poses no theoretical constraint on the ability of the central bank to determine the price level. If the central bank has difficulties measuring the value premium, then these estimation errors will lead to some discrepancy between target and actual prices. These discrepancies are likely of the same order as those arising from mismeasuring the natural rate of interest in the conventional application of the Taylor rule. Moreover, with the wealth of data on interbank markets and on spreads between interest rates in those markets and in treasury bills, repos, and other money markets, there is no lack of real time data with which to measure $\chi_{t}$ and to adjust the payment-on-reserves process to these spreads.

\subsection{Three micro-founded models of banks and reserves}

Many standard models of banking fit into the general setup we just described. This subsection briefly describes three of them, each leading to different measurements of $\chi_{t}$ in the data.

\subsubsection{Banks and costly state verification}

The costly state-verification assumption, as employed by Bernanke, Gertler and Gilchrist (1999), is an element of many models of credit frictions. In this model, an entrepreneur has limited net worth to finance its capital investment, which has a random payoff that is private information of the entrepreneur. At some cost, the state can be revealed to financiers. 
The optimal contract involves such a disclosure for a limited set of states. Bernanke and coauthors' tractable formulation shows that overall investment will increase proportionally with net worth, while the aggregate supply of external finance increases with the externalfinance spread between the return on capital and the return earned by the financier.

Reserves held by banks need no such monitoring, since they are always honored by the central bank. There are then two ways to think of banks in this setup. One is to view the bank as the financier, collecting deposits from households and lending them to entrepreneurs. In that case, with a banking sector that is competitive, the return on deposits is the same as the return on reserves. Because households can deposit funds with banks or buy government bonds, the return on deposits is the same as the return on bonds. In this case, there is no value premium: $\chi_{t}=0$. A second way is to think of banks as the entrepreneurs, who are being monitored by depositors. In that case, the return on reserves is equated to the return on capital. It exceeds the return on bonds by the external-finance spread. In that case, $\chi_{t}$ is equal to this external-finance spread.

\subsubsection{Banks and limited commitment}

A more recent model of banks focuses on the inability of banks to commit not to divert a share of the funds given to them by depositors. Gertler and Kiyotaki (2010) is a prominent example of this approach, which has also been incorporated in many models of monetary policy and inflation. In this model, bankers only repay the depositor if the value of staying in business is at least as large as the value from running away with a fraction of the current assets. A bank is able to collect more deposits if it has higher net worth, since a fraction of that net worth would be lost in case of default. At the same time, leverage is constrained by the limited amount of skin in the game that banks can pledge given their limited capital. This constraint gives rise to a positive spread between the return the bank can earn on its projects and the return it pays to depositors. This spread captures the marginal unit value of having extra net worth to the bank by relaxing its leverage constraint.

Again, there are two ways to view reserves in this setup, depending on whether the defaulting banker can run away with reserves or not. Of course deposits at the central bank could be seized by creditors, but a bank can instantly convert reserves to cash at the central bank, and cash is anonymous and easier to abscond with. So, which case one takes depends on view on how quickly the bank could convert reserves into banknotes and escape with them. In the case where reserves can be fully seized by creditors, then their return will be 
equated to the return paid to depositors, in which case $\chi_{t}=0$. In the case where reserves can only be partially seized, then their return will be equated to the return on the other assets of the bank, and like them earns a premium $\chi_{t}$, which now reflects the inability of banks to scale up their investments because of the limited commitment problem.

\subsubsection{Banks and fiscal default}

Reis (2016b) notes that reserves and government bonds behave differently in a fiscal crisis. While governments often default on the government bonds they issue, central banks almost never default on reserves. Because reserves are the unit of account, defaulting on them requires a reform of the currency and monetary system in the country. Of course, unexpected inflation is a way to equally reduce the payments on both reserves and government bonds.

Because banks can hold reserves, they have access to a safe asset in a fiscal crisis that other agents in the economy do not. A recent literature has emphasized the scarcity of safe assets in modern economies, which are needed for instance to use as collateral in financial transactions - see Gorton, Lewellen and Metrick (2012) and Caballero, Farhi and Gourinchas (2016). Banks will value their ability to hold reserves to relax their financial constraints.

In this case, the value premium $\chi_{t}$ has two origins. First, it is a sovereign default premium that government bonds must pay but reserves do not. Second, it captures the marginal relaxation of banks' financial constraints that reserves provide during a fiscal crisis. In the case of the United States, both are likely small, so $\chi_{t}=0$ for the Federal Reserve. For the ECB instead, there is significant cross-country variation in $\chi_{t}$, which can be approximately measured in different ways using sovereign spread, credit default swaps and many other financial prices, for example, Krishnamurthy, Nagel and Vissing-Jorgensen (2014). Measuring this premium and adjusting monetary policy to it has already for the past few years been a source of focus and research by the ECB in managing the monetary transmission mechanisms in the Euro area.

\section{Relation to the Literature}

Hall (1997) appears to be the first statement of the idea that the price level can be controlled by a security whose purchasing power is designed to be constant, although he noted that Irving Fisher proposed that the monetary unit could be a quantity of gold that is adjusted continuously. Hall observes that, in continuous time, a floating-rate note paying the current 
real interest rate always has a purchasing power of one, so letting that note be the monetary unit would result in a price level of one at all times.

Our paper starts from the observation that reserves remunerated in a particular way can mimic the security envisioned by Hall. Relative to Hall, we showed this in discrete time, for one-period reserves, for a general target $p^{*}$, and allowing for effects on output as well. The payment-on-reserves process is a more natural policy within the new-style of central banking, it is easier to implement, and it flexibly allows for an elastic price or inflation standard.

Hall (2002) also discusses the Chilean Unidad de Fomento, which is a parallel monetary unit with strictly constant purchasing power. It is defined as enough pesos to buy the costof-living bundle. Our process stabilizes the purchasing power of the transactional monetary unit, not a parallel unit. Moreover, our process makes clearer that the economic logic behind it is different from that of the gold standard, or any other commodity standard. In effect, we provide an affirmative answer to a question that has been raised about the UF - is there some way that the UF could become the single monetary unit of Chile?

\subsection{Relation to interest-rate rules}

A huge literature examines the conditions for determinacy of the price level, a surprisingly subtle issue. Cochrane (2011) contains a recent lengthy discussion, while Woodford (2003) is the classic reference. With a payment-on-reserves process, the price level is pinned exactly on target each period. Unlike the Taylor rule, it does not generate a difference equation describing potential equilibrium price trajectories that must be iterated over time to infinity and paired with some controversial boundary condition. Finally, while the payment on reserves must still satisfy the constraint that nominal interests are positive, once the zero lower bound no longer binds the determinacy of the price level is ensured globally without having to move forward beyond that date. Our process rules out some of the peculiar equilibria that plague Taylor rules in a liquidity trap - see the discussion in Cochrane (2016).

The literature on interest-rate rules also relies on the no-arbitrage condition between reserves and government bonds. But, in our case, only no-arbitrage between two successive periods is needed, not across an infinite number of them. Therefore, concerns about how agents form expectations far into the future, which are crucial for determinacy with interestrate rules, do not apply to our process - see Garcia-Schmidt and Woodford (2015) and Gabaix (2016). Our process also does not rely on linearizations, but they play an important role 
with interest-rate rules, as discussed by Benhabib, Schmitt-Grohe and Uribe (2002) and Christiano, Eichenbaum and Johannsen (2016). Finally, as we showed in section 5, the precise way in which reserves affect liquidity does not affect determinacy, unlike what happens with interest-rate rules (Schmitt-Grohe, Benhabib and Uribe, 2001).

Two papers in the Wicksell- and Taylor-rule tradition are closer to our process. Adao, Correia and Teles (2011) consider an interest-rate process where the central bank follows the log-linearized rule:

$$
i_{t}=r_{t}+\mathbb{E}_{t}\left(p_{t+1}\right)-p_{t}^{*}
$$

They pair this rule with a log-linearized Fisher equation relating nominal and real interest rates,

$$
i_{t}=r_{t}+\mathbb{E}_{t}\left(p_{t+1}\right)-p_{t}
$$

The only possible outcome is $p=p^{*}$. Loisel (2009) discusses a similar monetary policy rule in the context of a broader treatment of policy rules.

As these authors showed, these rules are fragile: If the policy interest rate responds to $\mathbb{E}_{t}\left(p_{t+1}\right)$ with a coefficient that even slightly deviates from one, then there are multiple explosive solutions for the price level. With a payment-on-reserves process instead, the price level is robustly pinned to the target and depends only on the easy-to-observe market interest rate. Expectations of future prices are already included in the nominal rate, so the central bank does not need to form or observe any forecasts.

\subsection{Relation to fiscal and monetary theories}

The fiscal theory of the price level also has some similarities with our approach as well as important differences. In that theory, the treasury issues nominal liabilities, which, via the government budget constraint, have a fixed real payoff in terms of expected present fiscal surpluses. In our setup, it is the central bank that issues a nominal liability, and it chooses the real payoff using the payment-on-reserves process. As Cochrane (1998) emphasizes, the fiscal theory of the price level can also be interpreted in terms of a no-arbitrage principle, like with our process, in the valuation of government bonds as claims on the finite stream of fiscal surpluses. But our process does not have to appeal to the government budget constraint as an equilibrium object; the central bank controls the real payment on reserves directly.

With the payment-on-reserves process, control of the price level remains with the monetary authority, so there is monetary dominance. Our process does not rely on non-Ricardian 
behavior by the fiscal authorities. The process can co-exist with concerns about fiscal backing of the central bank and coordination between fiscal and monetary policy - see Sims (2013).

Finally, relative to an older monetarist tradition dating back to Cagan (1956), our approach does not rely on there being a stable demand for money. It is perfectly consistent with the existence of a demand for liquidity, but it relies on a different mechanism to pin down the price level.

\section{Concluding Remarks}

We propose a new approach for central banks to control the price level. As in all theories of the price level, ours relies on the properties of a nominal government liability. Our novelty is to focus on reserves, which are the unit of account, default-free, voluntarily held by banks and potentially other investors, and with remuneration set by the central bank as its policy instrument.

Within the class of theories of price-level determination focusing on the central bank's control of an interest rate, the key economic force at play is an arbitrage condition in financial markets. Our novelty is to observe that by setting a payment on those reserves, arbitrage between one period and the next will pin down the price level, without needing to consider arbitrage into the infinite future. As in post financial-crisis work in macroeconomics, but almost absent from the price-level determination literature, we consider the role played by liquidity and credit frictions in financial markets. Together with mis-measurement of prices and returns, we show that it is easy to adapt our policy process to their presence.

This approach provides three equivalent policy proposals for a central bank. They all consist in announcing a payment on reserves, but differ only on whether that payment is stated in units of output, is indexed to the price level, or is stated in nominal terms. For each of them there is an easy-to-implement policy process that delivers a unique price level. We showed that this uniqueness is global. Moreover, the control errors in hitting the target can be linked to measurement errors on actual prices and interest rates, instead of theoretical objects such as the natural real interest rate. Therefore, we believe that our approach has practical policy advantages relative to the existing practices of central banks.

As almost all of the literature on determination of the price level, we have not provided a full account of how an equilibrium is achieved by specifying off-equilibrium strategies and how the economy behaves when the price level deviates from $p^{*}$. Future work may expand 
our work to "sophisticated implementation" as in Atkeson, Chari and Kehoe (2010), for instance following Bassetto (2002). 


\section{References}

Adao, Bernardino, Isabel Correia, and Pedro Teles, "Unique monetary equilibria with interest rate rules," Review of Economic Dynamics, 2011, 14 (3), 432-442.

Atkeson, Andrew, Varadarajan V. Chari, and Patrick J. Kehoe, "Sophisticated Monetary Policies," Quarterly Journal of Economics, 2010, 125 (1), 47-89.

Ball, Laurence, N. Gregory Mankiw, and Ricardo Reis, "Monetary Policy for Inattentive Economies," Journal of Monetary Economics, May 2005, 52 (4), 703-725.

Bassetto, Marco, "A Game-Theoretic View of the Fiscal Theory of the Price Level," Econometrica, 2002, 70 (6), 2167-2195.

Benhabib, Jess, Stephanie Schmitt-Grohe, and Martin Uribe, "Avoiding Liquidity Traps," Journal of Political Economy, June 2002, 110 (3), 535-563.

Bernanke, Ben S., Mark Gertler, and Simon Gilchrist, "The Financial Accelerator in a Quantitative Business Cycle Framework," in John B. Taylor and Michael Woodford, eds., Handbook of Macroeconomics, Elsevier, 1999, chapter 21, pp. 1341-1393.

Caballero, Ricardo J., Emmanuel Farhi, and Pierre-Olivier Gourinchas, "Safe asset scarcity and aggregate demand," American Economic Review, May 2016, 106 (5), 513-18.

Cagan, Phillip, "The Monetary Dynamics of Hyperinflations," in Milton Friedman, ed., Studies in the Quantity Theory of Money, The University of Chicago Press, 1956, pp. 25117.

Calvo, Guillermo A., "Staggered Prices in a Utility-Maximizing Framework," Journal of Monetary Economics, September 1983, 12 (3), 383-398.

Christiano, Lawrence J., Martin Eichenbaum, and Benjamin K. Johannsen, "Does the New Keynesian Model Have a Uniqueness Problem?," June 2016. Northwestern University manuscript.

Cochrane, John H., "A Frictionless View of U.S. Inflation," NBER Macroeconomics Annual, 1998, $13(1), 323-421$. 
_ _ "Determinacy and Identification with Taylor Rules," Journal of Political Economy, 2011, $119(3), 565-615$.

__ "The New Keynesian Liquidity Trap," June 2016. Hoover Institution, Stanford University.

Cúrdia, Vasco, Andrea Ferrero, Ging Cee Ng, and Andrea Tambalotti, "Has U.S. monetary policy tracked the efficient interest rate?," Journal of Monetary Economics, 2015, 70, $72-83$.

Fleckenstein, Matthias, Francis Longstaff, and Hanno Lustig, "The TIPS-Treasury Bond Puzzle," Journal of Finance, September 2014, 69 (5), 2151-2197.

Gabaix, Xavier, "A Behavioral New Keynesian Model," NBER Working Paper 22954 October 2016.

Garcia-Schmidt, Mariana and Michael Woodford, "Are Low Interest Rates Deflationary? A Paradox of Perfect-Foresight Analysis," NBER Working Paper 21614 October 2015.

Gertler, Mark and Nobuhiro Kiyotaki, "Financial Intermediation and Credit Policy in Business Cycle Analysis," in Benjamin M. Friedman and Michael Woodford, eds., Handbook of Monetary Economics, Vol. 3 of Handbook of Monetary Economics, Elsevier, January 2010, chapter 11, pp. 547-599.

and Peter Karadi, "QE 1 vs. 2 vs. 3...: A Framework for Analyzing Large-Scale Asset Purchases as a Monetary Policy Tool," International Journal of Central Banking, January 2013, 9 (1), 5-53.

Goodfriend, Marvin, "Central banking under the gold standard," Carnegie-Rochester Conference Series on Public Policy, 1988, 29, 85 - 124.

Gorton, Gary, Stefan Lewellen, and Andrew Metrick, "The Safe-Asset Share," American Economic Review, May 2012, 102 (3), 101-06.

Greenwood, Robin, Samuel G. Hanson, and Jeremy C. Stein, "The Federal Reserve's Balance Sheet as a Financial-Stability Tool," in "Designing Resilient Monetary Policy Frameworks for the Future," Jackson Hole Symposium: Federal Reserve Bank of Kansas City, August 2016. 
Hall, R. E., "Controlling the Price Level," Contributions to Macroeconomics, 2002, 2 (1).

Hall, Robert E., "Monetary Strategy with an Elastic Price Standard," in "Price Stability and Public Policy: A Symposium Sponsored by the Federal Reserve Bank of Kansas City" 1984.

__ "Irving Fisher's Self-Stabilizing Money," American Economic Review Papers and Proceedings, May 1997, 87 (2), 436-438.

and Ricardo Reis, "Maintaining Central-Bank Solvency under New-Style Central Banking," NBER Working Paper 21173 July 2015.

Holston, Kathryn, Thomas Laubach, and John Williams, "Measuring the Natural Rate of Interest: International Trends and Determinants," in "NBER International Seminar on Macroeconomics 2016," National Bureau of Economic Research, Inc, Jan-Jun 2016.

Krishnamurthy, Arvind, Stefan Nagel, and Annette Vissing-Jorgensen, "ECB Policies involving Government Bond Purchases: Impact and Channels," August 2014. Stanford University.

Lagos, Ricardo and Randall Wright, "A Unified Framework for Monetary Theory and Policy Analysis," Journal of Political Economy, June 2005, 113 (3), 463-484.

Loisel, Olivier, "Bubble-free policy feedback rules," Journal of Economic Theory, 2009, 144 (4), 1521-1559.

Mankiw, N. Gregory and Ricardo Reis, "Sticky Information versus Sticky Prices: A Proposal to Replace the New Keynesian Phillips Curve," Quarterly Journal of Economics, November 2002, 117 (4), 1295-1328.

and __ , "Imperfect Information and Aggregate Supply," in Benjamin Friedman and Michael Woodford, eds., Handbook of Monetary Economics, Vol. 3A, Elsevier: North Holland, 2010, chapter 5, pp. 183-230.

Reis, Ricardo, "Funding Quantitative Easing to Target Inflation," in "Designing Resilient Monetary Policy Frameworks for the Future," Jackson Hole Symposium: Federal Reserve Bank of Kansas City, August 2016. 
_ _ "QE in the future: the central bank's balance sheet in a fiscal crisis," NBER Working Paper 22415 June 2016.

Samuelson, Paul A., "An Exact Consumption-Loan Model of Interest With or Without the Social Contrivance of Money," Journal of Political Economy, 1958, 66 (6), 467-482.

Schmitt-Grohe, Stephanie, Jess Benhabib, and Martin Uribe, "Monetary Policy and Multiple Equilibria," American Economic Review, March 2001, 91 (1), 167-186.

Sidrauski, Miguel, "Rational Choices and Patterns of Growth in a Monetary Economy," American Economic Review, Papers and Proceedings, 1967, 57, 534-544.

Sims, Christopher A., "Paper Money," American Economics Review Papers and Proceedings, May 2013, $103(3), 563-584$.

Woodford, Michael, Interest and Prices, Princeton, New Jersey: Princeton University Press, 2003. 


\section{Appendixes}

\section{A Financial Stability with a Constant-Net-Worth Rule}

If the central bank's independence mandate requires it to choose dividends $d_{t}$ such that the net worth of the central bank is constant, then $n_{t}=n_{t+1}$ implies that:

$$
-\frac{v_{t+1}}{p_{t+1}}+\frac{b_{t+1}}{\left(1+i_{t+1}\right) p_{t+1}}=n_{t}
$$

The law of motion for reserves in equation (46) can be rearranged as follows:

$$
\frac{v_{t+1}}{p_{t+1}}-\frac{b_{t+1}}{p_{t+1}\left(1+i_{t+1}\right)}=\left(1+x_{t}\right) v_{t}-s_{t+1}+d_{t+1}-\frac{b_{t}}{p_{t+1}} .
$$

Adding both sides of these equations gives the solution for dividends:

$$
d_{t+1}=s_{t+1}+r_{t} n_{t}-\left(1+r_{t}\right) n_{t}-\left(1+x_{t}\right) v_{t}+\frac{b_{t}}{p_{t+1}}
$$

Recalling the definition of $n_{t}$ in terms of assets and liabilities and rearranging gives:

$$
d_{t+1}=s_{t+1}+r_{t} n_{t}-\frac{b_{t}}{p_{t}}\left(\frac{1+r_{t}}{1+i_{t}}-\frac{p_{t}}{p_{t+1}}\right)+\left[1+r_{t}-\left(1+x_{t}\right) p_{t}\right]\left(\frac{v_{t}}{p_{t}}\right) .
$$

Finally, note that the last term is zero under the payment-on-reserves process for monetary policy. This gives the desired result in equation (47).

\section{B Micro-Founded Models of Price Adjustment}

The model of section 2 is modified as follows: First, the representative agent now has period preferences given by $u\left(c_{t}, l_{t}\right)$. The Euler equation for real bonds therefore becomes:

$$
\mathbb{E}_{t}\left[\left(\frac{\beta u_{c}\left(c_{t+1}, l_{t+1}\right)}{u_{c}\left(c_{t}, l_{t}\right)}\right)\left(1+r_{t}\right)\right]=1
$$

Log-linearizing around a steady state with $(\bar{c}, \bar{l})$ gives the first equation of the reduced-form model, where $\sigma=-\bar{c} u_{c} c(\bar{c}, \bar{l}) / u_{c}(\bar{c}, \bar{l})$.

Second, the problem of the firm can be generalized to have a production function $y_{i t}=$ $f\left(l_{i t}\right)$. By standard steps (see Woodford (2003)), the price set by a firm that just updated its information is: $\hat{p}_{t}+\alpha \hat{y}_{t}$ where $\alpha>0$ is a complicated expression involving the degree of returns to scale and the relative disutility of labor supply. It is the elasticity of marginal costs with respect to aggregate output, affected both by decreasing returns to scale with respect 
to individual output and by the fact that higher output comes with higher consumption and thus higher real wages required to supply the same amount of labor by households.

With sticky information, $\lambda$ firms are randomly drawn and allowed to update their prices and they set their price equal to their expected desired price, at all dates in the future to $\mathbb{E}_{t}\left(p_{t+j}+\alpha y_{t+j}\right)$. With sticky prices, instead an individual firm that adjusts today chooses its price equal to the weighted average of its expected future prices: $\left.\lambda \sum_{j=0}^{\infty} \beta^{j}(1-\lambda)^{j}\right) \mathbb{E}_{t}\left(p_{t+j}+\right.$ $\left.\alpha y_{t+j}\right)$. Log-linearizing these two relations gives the two Phillips curves in those models.

\section{Determinacy Proofs}

For the Calvo sticky price model, the characteristic polynomial is:

$$
P(x)=x^{3}-\left(2+\frac{1}{\beta}\right) x^{2}+\left[1+\frac{2}{\beta}+\frac{\kappa}{\beta \sigma}\right] x-\frac{1}{\beta} .
$$

It is easy to see that $P(1)=-\kappa /(\sigma \beta)<0$ while $P(-1)=4+4 / \beta+\kappa /(\beta \sigma)>0$. Therefore, the system has two eigenvalues outside the unit circle, and one inside: the condition for saddle path stability.

Turn next to the accelerationist model. In matrix notation, the system is:

$$
\left[\begin{array}{c}
\tilde{y}_{t+1} \\
\tilde{\pi}_{t} \\
\tilde{p}_{t}
\end{array}\right]=\underbrace{\left[\begin{array}{ccc}
1+\kappa / \sigma & 1 / \sigma & 1 / \sigma \\
\kappa & 1 & 0 \\
\kappa & 1 & 1
\end{array}\right]}_{A}\left[\begin{array}{c}
\tilde{y}_{t} \\
\tilde{\pi}_{t-1} \\
\tilde{p}_{t-1}
\end{array}\right]
$$

There is one non-predetermined variable, $\tilde{y}_{t}$, and two endogenous predetermined variables, $\tilde{\pi}_{t}$ and $\tilde{p}_{t-1}$. Thus, for the system to have a unique solution it is required that the matrix $A$ has one eigenvalue outside the unit circle and two inside.

The characteristic polynomial of the matrix is:

$$
P(x)=x^{3}+\left[-(2+\beta)-\frac{\kappa}{\sigma}\right] x^{2}+(1+2 \beta) x-\beta
$$

and we need to check that one of its roots is above 1 , and the other two are below one in absolute value. Make the transformation: $x=(1+s) /(1-s)$. The polynomial becomes:

$$
P(s)=s^{3}+\left(\frac{4(1-\beta)+\frac{\kappa}{\sigma}}{4(1+\beta)+\frac{\kappa}{\sigma}}\right) s^{2}-\left(\frac{\kappa}{\left(4(1+\beta)+\frac{\kappa}{\sigma}\right) \sigma}\right) s-\left(\frac{\kappa}{\left(4(1+\beta)+\frac{\kappa}{\sigma}\right) \sigma}\right)
$$

and determinacy is now equivalent to this polynomial having one positive and two negative roots. Descartes's rule of sign shows that this is the case independently of parameters because 
the coefficient signs of $P(s)$ are ++-- , so there is one positive root, and the coefficient signs of $P(-s)$ are $=-++-$ implying two negative roots.

The case for the hybrid Phillips curve is almost identical, so we state only the $A$ matrix:

$$
A \equiv \frac{1}{(1-\phi) \sigma \beta}\left[\begin{array}{cccc}
\sigma & -\sigma \kappa & -\phi \sigma & 0 \\
(1-\phi) \beta & (1-\phi) \sigma \beta & 0 & (1-\phi) \beta \\
0 & 0 & (1-\phi) \sigma \beta & 0 \\
(1-\phi) \sigma \beta & 0 & 0 & (1-\phi) \sigma \beta
\end{array}\right]
$$

The characteristic polynomial after the $x=(1+s) /(1-s)$ transformation is:

$$
\begin{aligned}
P(s)= & \left(4+\frac{4(1+\phi)}{\beta(1-\phi)}+\frac{\kappa}{\beta \sigma(1-\phi)}\right) s^{4}+8\left(\frac{\beta(1-\phi)-\phi}{\beta(1-\phi)}\right) s^{3} \\
& -\left(\frac{\kappa+2 \sigma(1-\phi)(1-\beta)}{\beta \sigma(1-\phi)}\right) s^{2}+\frac{\kappa}{\beta \sigma(1-\phi)}
\end{aligned}
$$

Because there are two forward-looking variables, and two predetermined ones, for determinacy there should be two positive and two negative roots. The signs of the coefficients for $P(s)$ are $+?-+$ so there are two positive roots according to Descartes's sign rule. They are $+?-+$ for $P(-s)$ implying two negative roots.

\section{The New Monetarist Model}

In the centralized market, the representative household solves:

$$
\begin{aligned}
V^{C M}\left(\hat{v}_{t}, b_{t}\right) & =\max _{c_{t}, h_{t}, v_{t}, b_{t}}\left\{U\left(c_{t}\right)-h_{t}+\beta \mathbb{E}_{t}\left[V^{D M}\left(v_{t+1}, b_{t+1}\right]\right\}\right. \\
\text { s.t. } & p_{t} c_{t}+\frac{b_{t}}{1+i_{t}}+v_{t} \leq p_{t} w_{t} h_{t}+b_{t-1}+p_{t}\left(1+x_{t-1}\right) \hat{v}_{t}+T_{t}
\end{aligned}
$$

where $\hat{v}_{t}$ are the outstanding reserve balance of an agent entering the centralized market. This leads to the first-order conditions:

$$
\begin{aligned}
& U^{\prime}\left(c_{t}\right)-\lambda_{t} p_{t}=0 \\
& \lambda_{t} P_{t} w_{t}-A=0 \\
& \lambda_{t}=\beta \mathbb{E}_{t}\left[V_{v}^{D M}\left(v_{t+1}, b_{t+1}\right)\right] \\
& \lambda_{t}=\beta \mathbb{E}_{t}\left[V_{b}^{D M}\left(v_{t+1}, b_{t+1}\right)\right] \\
& V_{v}^{C M}\left(\hat{v}_{t}, b_{t}\right)=p_{t}\left(1+x_{t-1}\right) \lambda_{t} \\
& V_{b}^{C M}\left(\hat{v}_{t}, b_{t}\right)=\left(1+i_{t-1}\right) \lambda_{t}
\end{aligned}
$$


In the decentralized market, with probability $\sigma$ a household is assigned to one side of the decentralized market (i.e. buyer or seller) and with probability $(1-2 \sigma)$ it is inactive. The value of entering the decentralized market then is:

$V^{D M}\left(v_{t}, b_{t}\right)=\sigma\left[\chi u\left(q_{t}\right)+V^{C M}\left(v_{t}-d_{t}^{v}, b_{t}\right)\right]+\sigma\left[-e\left(q_{t}\right)+V^{C M}\left(d_{t}^{v}+v_{t}, b_{t}\right)\right]+(1-2 \sigma) V^{C M}\left(v_{t}, b_{t}\right)$

The inverse production function is $e_{t}=e\left(q_{t}\right)$. From this it follows that:

$$
\begin{aligned}
V_{v}^{D M}\left(v_{t}, b_{t}\right) & =V_{v}^{C M}\left(v_{t}, b_{t}\right)+\sigma\left[\chi u^{\prime}\left(q_{t}\right) \frac{\partial q_{t}}{\partial v_{t}}-V_{v}^{C M}\left(v_{t}, b_{t}\right) \frac{\partial d^{v}}{\partial v_{t}}\right] \\
& +\sigma\left[-e_{q}^{\prime}\left(q_{t}\right) \frac{\partial q_{t}}{\partial v_{t}}+V_{v}^{C M}\left(v_{t}, b_{t}\right) \frac{\partial d^{v}}{\partial v_{t}}\right] \\
V_{b}^{D M}\left(v_{t}, b_{t}\right) & =V_{b}^{C M}\left(v_{t}, b_{t}\right)
\end{aligned}
$$

Finally, when the representative buyer and the representative seller in the decentralized market meet, they make a Nash bargain:

$$
\max _{q_{t}, d_{t}^{v}}\left[\chi u\left(q_{t}\right)-U^{\prime}\left(c_{t}\right) \frac{d_{t}^{v}}{p_{t}}\right]^{\theta}\left[U^{\prime}\left(c_{t}\right) \frac{d_{t}^{v}}{p_{t}}-e\left(q_{t}\right)\right]^{1-\theta} \text { s.t. } \quad d_{t}^{v} \leq v_{t}^{b}
$$

Defining:

$$
g(q)=\frac{(1-\theta) e_{q}^{\prime}(q) \chi u(q)+\theta \chi u^{\prime}(q) e(q)}{\theta \chi u^{\prime}(q)+(1-\theta) e_{q}^{\prime}(q)}
$$

the optimality condition from the Nash bargaining problem together with the equilibrium condition that all the reserves are used for purchases becomes:

$$
v=d^{v}=g(q) p w .
$$

From this it follows that $\partial d^{v} / \partial v=1$ and $\partial q / \partial v=1 / w p g_{q}^{\prime}(q)$

Combining all three problems it is then just a matter of algebra to show that

$$
\begin{aligned}
& \mathbb{E}_{t}\left[\frac{\beta U^{\prime}\left(c_{t+1}\right) p_{t}}{U^{\prime}\left(c_{t}\right) p_{t+1}}\left(1+i_{t}\right)\right]=1 \\
& \mathbb{E}_{t}\left[\frac{\beta U^{\prime}\left(c_{t+1}\right) p_{t}}{U^{\prime}\left(c_{t}\right) p_{t+1}}\left(1+x_{t}\right) p_{t+1}\right]=1-\frac{\sigma \beta}{\lambda_{t}} \mathbb{E}_{t}\left[\frac{\chi u^{\prime}\left(q_{t+1}\right)-e_{q}^{\prime}\left(q_{t+1}\right)}{w_{t+1} p_{t+1} g_{q}^{\prime}\left(q_{t+1}\right)}\right]
\end{aligned}
$$

The result in lemma 2 then follows immediately. 